DEMOGRAPHIC RESEARCH

VOLUME 33, ARTICLE 17, PAGES 499-524

PUBLISHED 8 SEPTEMBER 2015

http://www.demographic-research.org/Volumes/Vol33/17/

DOI: 10.4054/DemRes.2015.33.17

Research Article

Neighborhood-health links: Differences between

rural-to-urban migrants and natives in Shanghai

\title{
Danan Gu
}

Haiyan Zhu

Ming Wen

(c) 2015 Danan Gu, Haiyan Zhu \& Ming Wen.

This open-access work is published under the terms of the Creative Commons Attribution NonCommercial License 2.0 Germany, which permits use, reproduction \& distribution in any medium for non-commercial purposes, provided the original author(s) and source are given credit. See http://creativecommons.org/licenses/by-nc/2.0/de/ 


\section{Table of Contents}

$\begin{array}{lll}1 & \text { Introduction } & 500\end{array}$

2 Literature review $\quad 501$

3 Methods 503

3.1 Study population 503

3.2 Perceptions of neighborhood contextual variables 504

3.3 Health outcomes 505

$\begin{array}{ll}3.4 & 505\end{array}$

$\begin{array}{llr}4 & \text { Statistical analysis } & 507\end{array}$

5 Results $\quad 507$

6 Discussion 510

$7 \quad$ Limitations and implications $\quad 512$

8 Acknowledgments $\quad 514$

$\begin{array}{ll}\text { References } & 515\end{array}$

Appendix $\quad 524$ 


\title{
Neighborhood-health links: Differences between rural-to-urban migrants and natives in Shanghai ${ }^{1}$
}

\author{
Danan $\mathrm{Gu}^{2}$ \\ Haiyan $\mathrm{Zhu}^{3}$ \\ Ming Wen ${ }^{4}$
}

\begin{abstract}
BACKGROUND

It is well known that migrant workers tend to have different perceptions of neighborhood environments than urban natives. However, less is known about how these differences in perception may be linked to the health of members of these two groups.
\end{abstract}

\section{OBJECTIVE}

We investigated differences in links between perceived neighborhood social and physical environments and three health outcomes, self-rated health, social stress, and chronic conditions, between rural-to-urban migrants (migrant workers) and Shanghaiborn native urban residents in China.

\section{METHODS}

Data used in this study were based on a survey of 477 rural-to-urban migrants and 546 native urban residents aged 18-64, conducted in Shanghai in 2008. Logistic regression analyses were performed to model relationships for migrant workers and native residents.

\section{RESULTS}

We found that among migrant workers, more positive perceptions of neighborhood social environments (social cohesion and safety) were linked to better self-rated health and lower levels of perceived stress but were not linked to chronic disease conditions; there were also no links between perceptions of physical environments and any of the three health outcomes of this study among migrant workers. By contrast, among urban

\footnotetext{
${ }^{1}$ Disclaimer: The views expressed in this paper are solely those of the authors and do not necessarily reflect those of the United Nations, Virginia Tech, and University of Utah.

${ }^{2}$ United Nations Population Division, New York, U.S.A. E-Mail: gudanan@yahoo.com, gud@un.org.

3 Department of Sociology, Virginia Tech, U.S.A. E-Mail: zhuh09@vt.edu.

4 Department of Sociology, University of Utah, U.S.A. E-Mail: ming.wen@soc.utah.edu.
} 
natives, more positive perceptions of neighborhood social environments were linked to lower odds of chronic disease conditions but were not linked to self-rated health and perceived stress; more positive perceptions of physical environments (amenities and air quality) were linked with lower odds of social stress and of chronic disease conditions.

\section{CONCLUSIONS}

Neighborhood social and physical environments affected the health of migrant workers and urban natives differently.

\section{Introduction}

An abundant literature has documented the important role that neighborhood context plays in a variety of individual outcomes ranging from life chances and life trajectories to lifestyles and health outcomes, regardless of individual background (e.g., Bjornstrom and Kuhl 2014; Choi 2009; Ellis and Almgren 2009; Kawachi and Berkman 2003; Kim et al. 2011; Kimbro 2009; Li and Wu 2010; Logan, Alba, and Zhang 2002; Telles and Ortiz 2008; Wen, Hawkley, and Cacioppo 2006; Wen and Wang 2009). Evidence further suggests that perception of neighborhood environments is a crucial link between objective neighborhood conditions and health, and that perceived neighborhood contexts may even have stronger impacts on individual outcomes than objective neighborhood environments (Polling et al. 2014; Weden, Carpiano, and Robert 2008; Wen, Hawkley, and Cacioppo 2006). These neighborhood perceptions may vary across subgroups defined by socio-demographic background (Kamphius et al. 2010; O'Brien et al. 2014), such as immigrant status. Immigrants are often blamed for a rise in crime, violence, or social illness, which in turn affects the perceptions that both local residents and immigrants have about their neighborhood environments, especially in immigrant concentrated areas (Chiricos, McEntire, and Gertz 2001; Semyonov, Gorodzeisky, and Glikma 2012).

So far most evidence on these issues is based on studies conducted in Western societies, which may not be applicable to other social, economic, and cultural settings. In China, research on the link between neighborhood environments/contexts and health has recently emerged, focusing on rural-to-urban migrants (hereafter migrant workers) in big cities and reporting significant associations between neighborhood contexts and health outcomes (e.g., Chen and Chen 2015; Palmer, Perkins, and Xu 2011; Wen et al. 2010). However, little work has been done to evaluate how the associations between neighborhood perceptions and health may differ between migrant workers and local residents. The large-scale rural-to-urban migration that has swept across all major Chinese cities is considered the largest population movement in human history in terms 
of migrant population size (China National Bureau of Statistics (NBSC) 2012). Migrant workers may be differently influenced by contextual exposures than urban natives, which could likely have far-reaching implications for urban health promotion. China's unique social setting has undergone rapid urbanization and industrialization since the reform and opening era in the late 1970s. Shanghai is the largest and one of the fastest growing cities in China, with migrant workers comprising $45 \%$ of the total de facto population of Shanghai in the 2010 census (NBSC 2012). Therefore, Shanghai offers a good sample for studying these issues.

\section{Literature review}

It has long been recognized that neighborhood environments function as contextual regulators that shape individual behaviors, lives, and opportunities (e.g., Everson-Rose et al. 2011). Neighborhood contextual factors can be roughly categorized into physical (built/natural) environments and social environments (Diez Roux 2001; Hyman 2004; Macintyre, Ellaway, and Cummins 2002; Schulz et al. 2005). Examples of neighborhood physical environments are neighborhood amenities (e.g., infrastructures or facilities such as hospitals, schools, parks, libraries, and churches) and air quality. Examples of neighborhood social environments are social cohesion, solidarity, and safety (e.g., trust, helpfulness, friendliness, good relationships between neighbors, low crime rate) (Forst et al. 2010; Sallis et al. 2006).

Neighborhood environments can be measured either objectively or subjectively. Objective measurements are usually obtained from census, administrative, archive, or GIS data, or from investigators' independent observations (Diez Roux and Mair 2010; Elo et al. 2009). Subjective measures are mainly collected in survey questionnaires by asking participants to report their own perceptions about their neighborhood environments (Diez Roux 2001). Evidence shows that both types of measurement are reliable and valid instruments for measuring neighborhood environments and their effects on health (Brownson et al. 2009; Hadley-Ives et al. 2000; Kamphius et al. 2010; Kawachi and Berkman 2003; Jack and McCormack 2014; Poortinga, Dunstan, and Fone 2007; Schulz et al. 2013; Wen, Hawkley, and Cacioppo 2006; Yen et al. 2008).

Many studies have documented significant associations between objective or subjective neighborhood factors and individual health outcomes, net of personal characteristics (see Balfour and Kaplan 2002; Clarke et al. 2014; Diez Roux 2001; Do et al. 2008; Ellaway, Macintyre, and Kearns 2001; Kawachi and Berkman 2003; Siordia and Saenz 2013; Wen, Hawkley, and Cacioppo 2006; Weden, Carpiano, and Robert 2008; Yen et al. 2008). For example, the availability of recreational parks and bus routes has been found to be positively associated with levels of physical activity 
participation, thus indirectly promoting health. By contrast, environmental hazards such as air pollution, spatial proximity to solid waste sites, and noise are confirmed to be negative contextual correlates of individual-level health in the US (Geelen et al. 2009; Downey 2006; Wen, Hawkley, and Cacioppo 2006) as well as in China (Chen et al. 2012; Wen et al. 2010).

It can be argued that neighborhood resources and hazards impact individual outcomes when they are recognized by the individual, mainly through judgments about the meanings of environments derived from understanding, beliefs, criteria, and experiences that are relevant to his/her daily life. This individual recognition, or perception, can vary by life experience and personal characteristics (Altschuler, Somkin, and Adler 2004; Brownson et al. 2009; Diez Roux 2001; O'Brien et al. 2014; Roosa et al. 2009; Vega et al. 2011; Wachs 1999; Weden, Carpiano, and Robert 2008; Wen, Hawkley, and Cacioppo 2006; Wu 2012). Consequently, subjective neighborhood perceptions may affect the health and behavior of residents more strongly than do objective neighborhood characteristics that residents may or may not recognize (Polling et al. 2014; Weden, Carpiano, and Robert 2008; Wen, Hawkley, and Cacioppo 2006). Evidence on the association between perceived neighborhood environments and health is abundant (Beenackers et al. 2013; Hill et al. 2012; Kamphius et al. 2010; Boslaugh et al. 2004). For example, previous work has shown that higher levels of perceived neighborhood social cohesion, solidarity, and safety are associated with increased levels of social support and psychological well-being (O’Campo, Salmon, and Burke 2009) and increased likelihood that residents adopt healthy behaviors (Beenackers et al. 2013; Kawachi and Berkman 2000). By contrast, negative neighborhood perceptions are linked to higher levels of stress and depression and lower levels of neighborly trust and self-esteem (Ross and Jang 2000; Ross, Mirowsky, and Pribesh 2001).

However, these neighborhood effects may not be uniform across different sociodemographic groups. Limited evidence shows that the neighborhood-health link can be moderated by individual-level factors such as class (Diez Roux et al. 1997) and ethnicity (Browning, Cagney, and Wen 2003; Stafford, Newbold, and Ross 2011). Migrant status can also be a moderating factor. For example, a recent study conducted in China found that perceived living environment and neighborhood safety were only associated with mental health among urban natives, not among migrant workers (Chen and Chen 2015). However, the authors did not elaborate why this was the case, and thus the possible mechanism is unclear.

Motivated by the literature reviewed above, this study aims to explore how associations between perceived neighborhood contexts and health outcomes may differ between migrant workers and urban natives. Specifically, we aim to examine associations between perceptions of social physical environments with three health outcomes (self-rated health, social stress, and chronic disease condition). In theory, 
migrants may be less influenced by their neighborhood environments because they spend little time in their neighborhoods and are unfamiliar with their neighborhood surroundings due to longer work hours (Chen 2013; Li et al. 2009). On the other hand, migrants can be more affected by neighborhood environments, given that they tend to be more socioeconomically disadvantaged compared to their urban counterparts and could potentially benefit more from public resources (Chen 2011; Chen and Chen 2015). Migrants may be particularly sensitive to neighborhood social environments in that they are newcomers to the city and are challenged by all sorts of settlement stressors; thus they may benefit more from social integration, which could provide a community-level buffer against stress. Given these ambivalent forces, it is hard to rationalize an a priori hypothesis about the direction in which migrant status may moderate the neighborhood-health link. This remains an empirical question. To the best of our knowledge, this study is among the first to investigate this question and to present the associations between neighborhood perceptions and health outcomes separately for migrant workers and urban natives in China.

\section{Methods}

\subsection{Study population}

Data used in this study were from the 2008 Shanghai Rural-to-Urban Migrant Worker Survey of the adult population aged 18 to 64 in Shanghai, conducted by the Institute of Demographic Research, Fudan University (Wen et al. 2010). The survey was sponsored by the Chinese University of Hong Kong, Fudan University, and the University of Utah, and was approved by the survey and behavioral research ethics committee at the Chinese University of Hong Kong (See Wen et al. 2010 for more details). Because approximately $80 \%$ of migrants live on the outskirts of Shanghai, the survey covered two urban districts (Yangpu and Putuo, in the city proper) and three suburban districts (Baoshan, Jiading, and Songjiang). In Yangpu, Putuo, and Jiading, 50 households were sampled from four randomly selected residents' committees in each of the districts. In Baoshan and Songjia, 200 households were sampled from one town from each district. In other words, 14 communities (residents' committees or towns) were selected in total. The 50 households in each community were divided into two groups with 25 each of migrant workers and Shanghai-born residents. These households were dispersed throughout the residents' committee in order to avoid geographical and occupational concentration. One person aged between 18 and 64 years old in each household was interviewed. All information was obtained through in-home interviews. The total sample size is 1,076, with 530 migrants and 546 Shanghai-born residents. Of the 530 
migrants, 477 respondents were from rural areas or small towns and 53 were from other cities. The total valid sample used in this study is $1,023(=477+546)$.

The study collected information on respondents' personal demographics, family and household structure, living arrangements, socioeconomic and work conditions, availability and accessibility of medical care and insurances, social network and social relations, smoking and drinking behaviors, mental and psychological well-being, selfrated health, chronic diseases, and neighborhood characteristics. This is one of only a few relatively large surveys in China based on an approximate-match design to compare migrant workers with local urban natives.

\subsection{Perceptions of neighborhood contextual variables}

In the survey, a neighborhood refers to a residential community; each neighborhood (or community) has a neighborhood committee (or community committee, i.e., Juweihui), with a total population normally ranging from 1,000 to 9,000 in the case of Shanghai (Shanghai Municipal Statistical Bureau 2011). We relied on self-reported neighborhood characteristics to capture neighborhood built physical environments in terms of neighborhood amenities and air quality and social environments in terms of social cohesion and safety.

We used four dichotomous questions to measure neighborhood social cohesion: whether residents in the neighborhood were helpful and friendly; whether neighbors had a good relationship; whether neighbors trusted each other; and whether the respondents knew many people in the neighborhood. Each question was coded 1 if the respondent agreed and 0 otherwise. The Cronbach's alpha coefficient of these four items was 0.81 , which was above the threshold of 0.7 for group comparison (Nunnally 1994). This result indicated relatively good consistency and reliability across the four items. We then generated a neighborhood cohesion index by summing these four dichotomous variables. The index had a score ranging from 0 to 4 . Neighborhood safety was measured by whether the respondents had security concerns when walking alone at night in his/her immediate community and whether the respondents had security concerns associated with his/her immediate community. Neighborhood safety measured dichotomously and summed for an index score ranging from 0 to 2 .

We constructed the index of neighborhood amenities based on eight items that indicate whether there was a library, cinema, gym, park, bus or subway station, restaurant/bar/mobile dining car, primary school, and middle school in the community. These eight items had good consistency and reliability with a Cronbach alpha coefficient of 0.83 . We then created a neighborhood infrastructure index by summing the eight dichotomous variables with scores ranging from 0 to 8 . To measure 
neighborhood air quality, we used two self-rated dichotomous variables reflecting whether the indoor or outdoor air quality was good. We summed these with scores ranging from 0 to 2 . According to the nature of these two sets of variables, we considered social cohesion and safety as social environments, whereas we considered amenities and air quality as physical environments.

\subsection{Health outcomes}

Three health outcomes were examined: self-rated overall health, chronic disease conditions, and perceived stress. Self-rated health was divided into five categories (excellent, very good, good, fair, and poor) and then dichotomized into poor (fair/poor) versus good (excellent/very good/good) due to its skewed distribution. Chronic disease condition was self-reported. The respondent was required to answer whether a doctor or nurse had told him/her that he/she had any of the following twelve diseases around the time of the survey: asthma, diabetes, hypertension, high cholesterol, cardiovascular diseases, heart diseases, stroke, arthritis, dementia, cancer, hepatitis A, hepatitis B, and sexually transmitted diseases. We dichotomized the chronic disease condition into having one or more diseases vs. none.

Perceived stress was assessed using Cohen's perceived stress scale (Cohen, Kamarck, and Mermelstein 1983) with a few modifications to fit the Chinese context (Wen et al. 2010). The scale included eight items with an alpha coefficient of 0.89 , asking how often in the last month the respondent had: (1) dealt successfully with dayto-day problems and annoyances; (2) felt that he/she was effectively coping with important changes that were occurring in his/her life; (3) felt confident about his/her ability to handle his/her personal problems; (4) felt that things were going his/her way; (5) been able to control irritations in his/her life; (6) felt that he/she was on top of things; (7) found himself/herself thinking about things that he/she wants to accomplish; and (8) been able to control the way he/she spends his/her time. There were five response categories: never, occasionally, sometimes, often, and always. We coded the respondents as not suffering from social stress if they answered "often" or "always" for all eight items, and coded the respondents as suffering from social stress if they answered "never," "occasionally," or "sometimes" to any of the eight items.

\subsection{Control variables}

A range of confounders were controlled for, including age, sex, current residence (city proper vs. suburb), years of schooling $(<12,12$, and $>12)$, income, having health 
insurance in Shanghai (yes vs. no), marital status (married vs. unmarried), social support, health practice, body mass index (BMI), and health condition in the past. The selection of these confounding factors was based on evidence that these factors are linked to health and neighborhood contexts and may confound the associations of our key interest: perceived neighborhood physical and social environments and health (e.g., Ellis and Almgren 2009; Logan, Alba, and Zhang 2002; Semyonov, Gorodzeisky, and Glikma 2012; Wen and Wang 2009).

A scale of social support was constructed based on the extent of the respondent's agreement to the following nine statements: "I am able to find a friend or colleague easily if going on an outing for a day", "have a person or persons with whom I can share private worries and fear when in need", "find someone to help take care of daily chores", "find someone to watch a movie with", "know the appropriate person to talk to when in need", "find people to share lunch with", "find someone by phone for help when in need within 15km from my home", "find someone to help when moving", and I am "often invited to parties". The four response categories were: fully agree, agree, disagree, and fully disagree, with corresponding scores from 4 to 1 . The Cronbach alpha coefficient of these nine variables was 0.72. We summed these up and then dichotomized them into high support (score of 27 or higher) versus low support (score of 26 or lower). Other categorizations were also tested and the results were only slightly altered.

Health practice was measured by items asking whether the respondent regularly preformed exercise (yes vs. no) and ate breakfast (yes vs. no). Body mass index (BMI) was calculated by the self-reported weight $(\mathrm{kg})$ divided by the square of self-reported height (m). We then classified BMI into less than 18.5, 18.5-24.9, 25.0-29.9, and 30.0 or greater, following the standardized classification (WHO 2000). Because there were only 10 persons with a BMI greater than 30 , we combined the last two groups as 25.0 or higher. A variable reflecting the past health condition was included in the analysis and it was measured by a question asking whether a respondent had ever had a disability in the past that had made it impossible for him or her to work for one or more years.

As indicated in the literature, neighborhood population composition in terms of race, ethnicity, and nativity or citizenship could affect an individual's health and perception of amenities available in the local community (e.g., Bécares, Nazroo, and Stafford 2009; Burton and Jarrett 2000; Poortinga, Dunstan, and Fone 2007). A dichotomous variable of whether migrant workers outnumbered native Shanghai-born residents in the neighborhood at the time of survey (yes vs. no) was thus added to the analysis. 


\section{Statistical analysis}

We examined the associations between four aspects of neighborhood context and three health outcomes with separate logistic regressions for two groups: migrant workers and urban natives (i.e., Shanghai-born residents), controlling for various confounders. The separation of migrant worker and urban native was supported by significant differences in regression coefficients from supplementary analyses between these two groups (results available upon request). Two nested models for each subgroup were performed. Model I controlled for age, sex, current geographical residence, and community type in terms of whether migrant workers outnumbered Shanghai-born people. Model II added years of schooling, income, having health insurance in Shanghai, marital status, social support, health practice, BMI, and health condition in the past. All models were run using the STATA 13.1 software package. Considering our moderate sample size and our inclusion of a number of covariates in the models, we used a significance level of 0.1 , which is acceptable in social science research (Woodward 2004). It is suggested that a 0.1 level can be used when sample size is relatively small (Labovitz 1968). Our supplementary power analyses showed that although the sample size was not large, it could yield adequate statistical power to draw conclusions (see the table in the Appendix). Nevertheless, when interpreting the results, we are cautious about the limitations of our sample size, which are discussed at the end of the paper.

\section{Results}

Table 1 presents sample statistics for the two subsamples: migrant workers and urban natives. Overall, migrant workers tended to be healthier than urban natives in terms of self-rated health, perceived social stress, and chronic conditions. For example, $47.3 \%$ of urban natives reported fair or poor health versus $34.2 \%$ of migrant workers. Differences in perceived neighborhood amenities and safety between migrant workers and natives were significant, whereas differences in perceived social cohesion and safety were small. More than one-third of migrant workers in our sample (34.5\%) lived in communities in which migrant workers outnumbered urban natives, whereas the corresponding proportion in the urban native sample was less than one-fifth (16.1\%). Migrant workers in our sample were younger than urban natives (34.6 vs. 42.1 years) and the migrant sample had a lower proportion of men. Migrant workers' socioeconomic conditions in terms of education, income, and having medical insurance were much lower than those of urban natives. Urban natives had a higher proportion of high social support, having breakfast every day, and regularly doing exercise than migrant workers. There was a slight difference in BMI between these two populations, 
Gu, Zhu \& Wen: Neighborhood-health links: Differences between migrants and natives in Shanghai

with lower BMI found in migrant workers. Migrant workers also had a lower proportion of work leave for one year or more due to poor health.

Table 1: $\quad$ Sample distribution, 2008

\begin{tabular}{|c|c|c|c|}
\hline Variables & $\begin{array}{l}\text { Shanghai-born } \\
\text { urban native } \\
\text { sample }\end{array}$ & $\begin{array}{l}\text { Migrant worker } \\
\text { sample }\end{array}$ & $\begin{array}{c}\text { Significance } \\
\text { (chi square test or } t \\
\text { test) }\end{array}$ \\
\hline Total No. of respondents & 546 & 477 & --- \\
\hline \multicolumn{4}{|l|}{ Health outcomes } \\
\hline$\%$ Self-rated poor/fair health & 47.25 & 34.17 & 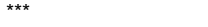 \\
\hline$\%$ perceived social stress & 10.99 & 10.27 & n. s. \\
\hline$\%$ having $1+$ chronic disease & 37.18 & 16.35 & 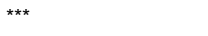 \\
\hline \multicolumn{4}{|l|}{ Neighborhood assets } \\
\hline Mean score of neighborhood cohesion (ranges $0-4$ ) & 0.98 & 1.08 & n. s. \\
\hline Mean score of neighborhood safety (ranges $0-2$ ) & 0.68 & 0.85 & 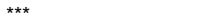 \\
\hline Mean score of neighborhood amenities (ranges $0-8$ ) & 4.73 & 4.25 & ** \\
\hline Mean score of good air quality (ranges $0-3$ ) & 2.43 & 2.49 & n. s. \\
\hline \multicolumn{4}{|l|}{ Covariates } \\
\hline $\begin{array}{l}\% \text { reporting the host community in which migrant workers } \\
\text { outnumbered Shanghai-born urban natives }\end{array}$ & 16.12 & 34.59 & 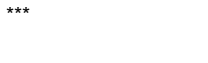 \\
\hline Mean age & 42.06 & 34.53 & $* \star \star$ \\
\hline$\%$ men & 54.03 & 45.49 & ** \\
\hline$\%$ living in city proper & 60.26 & 61.10 & n. s. \\
\hline$\%$ less than high school & 25.83 & 64.99 & $* \star \star$ \\
\hline$\%$ high school & 42.12 & 21.80 & 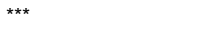 \\
\hline$\%$ college education or above & 32.05 & 13.21 & 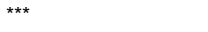 \\
\hline$\%$ income above 20,000 (RBM) & 51.47 & 37.95 & 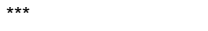 \\
\hline$\%$ having medical insurance in Shanghai & 96.70 & 52.00 & 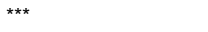 \\
\hline$\%$ currently married & 81.32 & 81.13 & n. s. \\
\hline$\%$ high social support & 73.63 & 66.88 & * \\
\hline$\%$ regularly doing exercise & 63.37 & 43.19 & 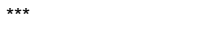 \\
\hline$\%$ having breakfast every day & 88.10 & 80.71 & 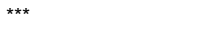 \\
\hline$\%$ body mass index $<18.5$ & 8.06 & 9.23 & * \\
\hline$\%$ body mass index $18.5-24.9$ & 67.58 & 75.05 & * \\
\hline$\%$ body mass index $25.0+$ & 24.36 & 15.72 & * \\
\hline$\%$ unable to work for one-year or more due to disability in the past & 5.13 & 4.19 & n.s. \\
\hline
\end{tabular}

Note: (1) t tests are applied to all continuous variables, whereas chi square tests are applied to all categorical variables. (2) n.s., not significant, $+p<0.1,{ }^{\star} p<0.05,{ }^{\star \star} p<0.01,{ }^{\star \star \star} p<0.001$.

Table 2 shows how perceived neighborhood environments were associated with each of the three health outcomes. Among urban natives, a one-unit increase in perceived social environments (neighborhood cohesion and safety) was associated with $14 \%$ and 27\% lower odds of having chronic conditions (Model I in the upper panel). However, neither of the two measures of perceptions of social environments was associated with poor self-rated health and social stress. Each one-unit increase in the availability of amenities was associated with $16 \%$ lower odds of perceived social stress. Greater perception of good air quality was associated with 19\% lower odds of having one or more chronic diseases. When other confounding factors were further adjusted in 
Model II, these associations were only slightly altered. In addition, perceptions of physical environments (amenities and air quality) were not associated with self-rated health among urban natives in either model.

Table 2: Odds ratios of associations between perceived neighborhood environments on health outcomes, migrant workers in Shanghai versus Shanghai-born urban natives

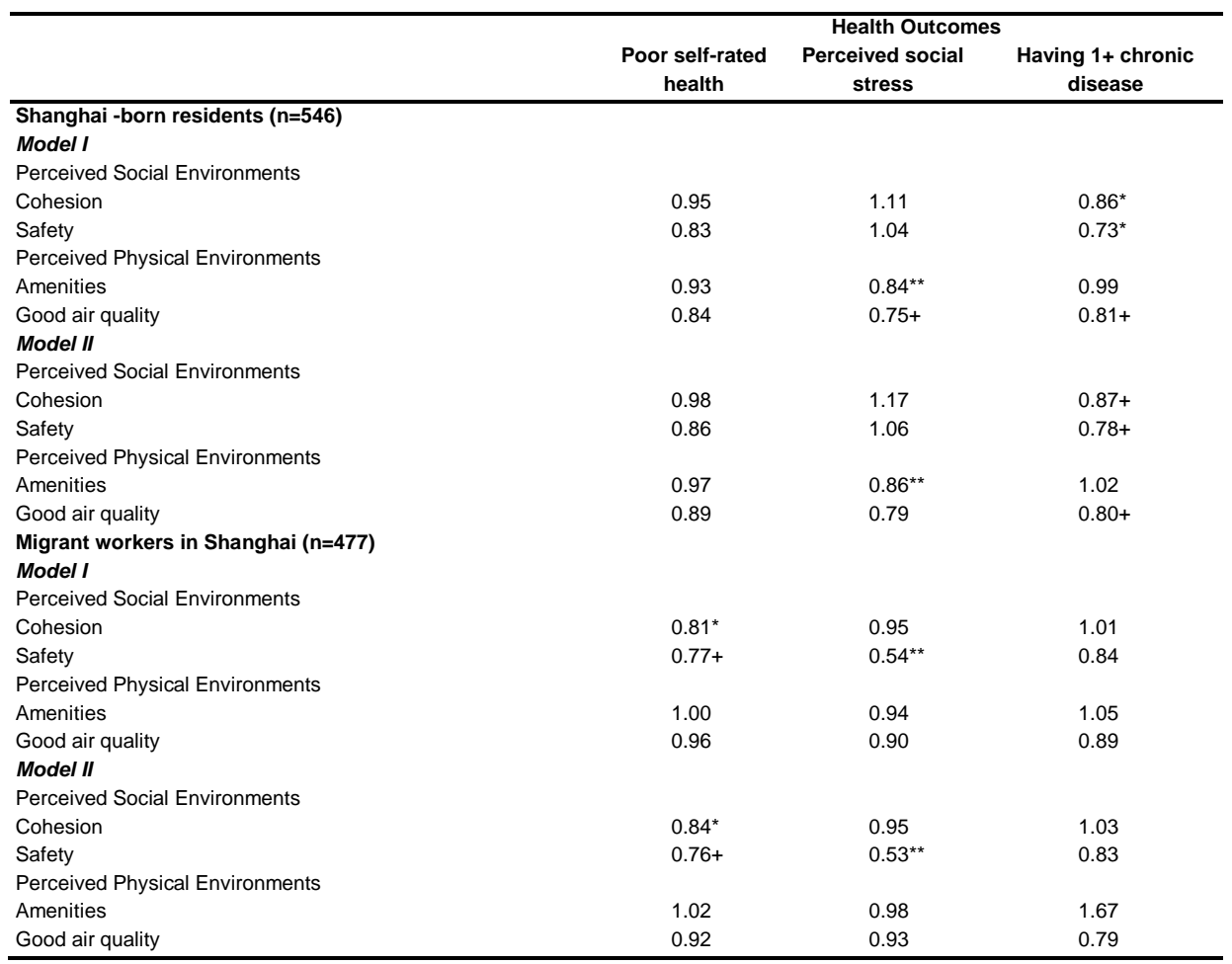

Note: (1) Odds ratios are based on binary logistic regressions.

(2) Model I includes age, sex, current residence (city proper vs. suburb), and whether the community population is dominated by Shanghai-born urban natives or not, in addition to three community variables. Model II further controls for education, income, having health insurance in Shanghai, marital status, social support, health practice (regularly doing exercise, having breakfast every day), BMI, and health condition in the past in terms of inability to work for one-year or more due to disability.

(3) $+p<0.1,{ }^{\star} p<0.05,{ }^{* \star} p<0.01,{ }^{\star \star *} p<0.001$.

The lower panel in Table 2 shows the associations between perceived environments and health outcomes among migrant workers. In contrast to urban residents, among migrant workers, perceptions about better social environments (social 
cohesion and safety) were associated with lower odds of poor self-rated health and perceived social stress, the two more subjectively measured health outcomes. For example, a one-unit increase in social cohesion was associated with $19 \%$ lower odds of reporting poor health when the demographics were controlled for and $16 \%$ lower odds when other covariates were further adjusted. Most noticeably, each additional score in perceived neighborhood safety was associated with a $46 \%-47 \%$ reduction in the odds of having perceived social stress and a $23 \%-24 \%$ reduction in the odds of self-rated poor health, regardless of the presence of covariates (Models I and II in the lower panel). Perceived social environment factors were not associated with the more objectively measured health outcome, chronic diseases. Perceived physical environment factors were not associated with any of the three health outcomes.

In addition to the analysis reported above, we conducted supplementary analysis to compare regression coefficients for migrant workers and natives (i.e., compared coefficients in Model II in the upper panel with those in Model II in the lower panel in Table 2 by using the seemingly unrelated regression command, -suest-, in the Stata package). Our results (available upon request) revealed that significant differences were found between these two populations for most coefficients. This further confirmed that neighborhood-health links for migrant workers and natives in Shanghai are significantly different.

\section{Discussion}

Our analysis of a 2008 dataset with 477 migrant workers and 546 local urban residents in Shanghai shows some differences in the neighborhood-health link between migrant workers and urban natives. One important finding is that migrant workers' perceptions of their social environments (social cohesion and safety) are significantly associated with their subjective health (self-rated health and social stress) but are not associated with chronic disease conditions. By contrast, urban natives' social environment perceptions are significantly associated with chronic conditions but are not associated with subjective health.

For migrant workers, the significant associations found between perceived social cohesion, safety, self-rated health, and social stress are likely due to their higher sensitivity to social environments. Plenty of evidence from China and Western societies suggests that migrant workers are more likely to suffer from poor mental health, social stress, and psychosocial problems than either local natives in destination or nonmigrants in their original, rural hometowns (Chen 2013; Hiott et al. 2008; Li et al. 2009; Ward and Tanner 2010; Weishaar 2008). This is because migrant workers may suffer from difficulties in social integration in urban destinations because of 
adjustments to new social-cultural environments, changes in traditions and lifestyle, barriers to accessing local services, intense and long working hours, and various types of discrimination (Chen 2013; Li et al. 2009). However, such disadvantages in psychological well-being can be reduced to some extent by having a good social and family support network. Some studies have reported that many migrant workers have trans-local kin-oriented or origin-oriented ties that could have the potential to foster greater self-esteem, a heightened sense of control, and an enhanced sense of meaningfulness in life (Jin et al. 2012; Li et al. 2009; Li and Wu 2010), leading to better subjective health. In this regard, we speculate that migrant workers with positive perceptions of social cohesion are those who likely have a psychologically supportive network that helps them relieve stress. By contrast, migrant workers with negative perceptions of social cohesion are those who likely do not have such a network. Following a similar reasoning, self-rated health could differ substantially among migrant workers, with those who receive support from a good social network reporting better self-rated health. Therefore, social support on a personal level may be a key mechanism through which neighborhood social cohesion is linked to subjective health outcomes. More research is clearly needed to confirm our speculations.

By contrast, urban natives tend to be physically less healthy compared to migrant workers, given that migration is a highly selective process based on health: sick people are less likely to migrate out in search of work, and migrant workers are more likely to return to their place of origin when they are sick due to lack of medical insurance in host communities (Chen 2011). In our sample, about $37 \%$ of natives suffered from one or more chronic disease compared to about $16 \%$ of migrant workers at the time of survey. Local natives who perceive higher social cohesion in neighborhood environments are more likely to have a relatively higher socioeconomic status compared to other natives; higher socioeconomic status also enables them to have their physical health checked more frequently and to get adequate treatment when in need, thus reducing the odds of suffering from illnesses. These differences by socioeconomic status among urban natives could lead to a significant association between perceived social environments and chronic disease conditions among natives.

Another important finding is that perceived physical environments (amenities and air quality) are associated with lower odds of social stress and chronic diseases among urban natives, but there are no associations between perceptions of neighborhood physical features and any of the three health outcomes of this study among migrant workers. This finding is in accordance with a recent study that found that the association between perceived living environments and depression is stronger among urban residents than among migrants (Chen and Chen 2015). We argue that native residents' greater access to amenities such as a recreational infrastructure may enable them to participate in physical activities, find relief from the stress of work, and enjoy 
life. In that regard, it is expected that a better perception of such physical environments indirectly promotes health among urban natives. In contrast to local urban natives, migrant workers are less familiar with neighborhood surroundings because their socioeconomically deprived status and longer working hours make access to public amenities either less affordable or less frequent.

In sum, we find that desirable neighborhood features affected the health of migrants and natives differently. Migrants' subjective health outcomes are more sensitive to neighborhood social environments, whereas urban natives benefit more from neighborhood physical environments. We also find significant associations between perceived neighborhood environments and health (Kawachi and Berkman 2000, 2003; Mair, Diez Roux, and Galea 2008; Sallis et al. 2009; Van Dyck et al. 2012; Wen, Hawkley, and Cacioppo 2006) and extend the neighborhood effect on health literature to urban migrants and native residents in China. Using a case from Shanghai, China, we identify differences in the perceived neighborhood context-health link between local urban natives and migrant workers. Evidence reported here underscores the importance of the perception of neighborhood environments in determining individual health outcomes, which may provide some insight into how neighborhood contexts affect health in other transitional countries.

\section{Limitations and implications}

The following limitations should be taken into account when interpreting our findings. First, although the validity and unique contribution of measures of self-perception of surrounding environments are widely recognized (Hadley-Ives et al. 2000; Kawachi and Berkman 2003), simultaneous applications of both objective and subjective measures of neighborhood environments, or some comprehensive index, would be preferable (Wen, Hawkley, and Cacioppo 2006; Schaefer-McDaniel et al. 2010). Second, population density, an important factor associated with residents' health (Kim et al. 2011; Mair, Diez Roux, and Galea 2008; McDonald, Forman, and Kareiva 2010), was not considered in our models due to unavailability of data. Third, mainly due to small sample size, we did not perform the analyses for men and women separately, even though they are likely to have distinct perceptions about the same contextual environments (Zhang et al. 2009). Thus, larger samples and separate analyses for men and women are recommended for future studies. Furthermore, because of the relatively small sample size, we used a relatively large $\mathrm{p}$ value $(\mathrm{p}<0.1)$ as a criterion for the statistical significance in some cases. We recognize that this increases the risk of Type I error. Fourth, we did not include length of residence of migrants in our analysis due to unavailability of data. Previous Western literature suggests that immigrants' length of 
residence in destination countries could be associated with perceptions of their surrounding environments (e.g., Alegria et al. 2007; Vega et al. 2011) and with some health outcomes (O'Brien et al. 2014). Finally, how different perceptions were associated with different health behaviors or psychological adjustments is not well modeled in the study, due to unavailability of data. We call for future studies to explore the underlying mechanisms between perceptions of neighborhoods and health behaviors or psychological adjustments.

Despite the limitations noted above, this study represents a novel effort in distinguishing differences in associations between perceptions of neighborhood contexts and several health outcomes in a transitional populous country. Our findings on different associations between perceptions of neighborhood environments and health outcomes between Shanghai-born residents and migrant workers suggest that migrant workers, lacking roots in Shanghai, tend to benefit more from social cohesion (social environments) than neighborhood amenities (physical environments). It is possible that migrants are less capable of taking advantage of neighborhood physical resources compared to natives. This implies that migrant workers could possibly benefit more from the improvement of social environments if they have more interaction with local natives and expand their kin-, family-, or origin-orientated networks to include local residents.

The migration of the rural labor force in China involves a shift in social and economic structures. As such, rural-to-urban migration is a crucial factor influencing China's industrialization and urbanization; thus, the fundamental solution of the "threedimensional rural issues" (concerning agriculture, countryside, and farmers) and the promotion of social equality and fairness (Démurger et al. 2009; Li and Wu 2010) both need to address the challenges of rural-to-urban migration. The poor social integration of migrant workers in host urban areas could pose a risk factor for social instability in general and a challenge for Shanghai in particular.

To address the challenges, policies that reduce various forms of disadvantage experienced by migrant workers in urban communities should be implemented and strengthened. Discriminative policies that reinforce disadvantaged institutional status such as legal restrictions on employment opportunities and unequal access to social welfares for migrant workers should be discontinued. Programs and strategies that increase migrant workers' awareness and utilization of their public physical facilities or resources should be advocated. 


\section{Acknowledgments}

Author's contribution: The study was initiated before Danan Gu was recruited by the UN. Danan Gu initiated and designed the study. Haiyan Zhu was involved in the study design. Danan Gu, Haiyan Zhu, and Ming Wen drafted and revised paper. Danan Gu performed the analyses. Ming Wen collected and prepared the data. Please send the correspondence to Danan Gu at gudanan@yahoo.com or Ming Wen at ming.wen@soc.utah.edu. We thank the three anonymous reviewers for their helpful comments. 


\section{References}

Alegria, M., Mulvaney-Day, N., Torres, M., Polo, A., Cao, Z., and Canino, G. (2007). Prevalence of psychiatric disorders across Latino subgroups in the United States. American Journal of Public Health 97(1): 68-75. doi:10.2105/AJPH.2006. 087205.

Altschuler, A., Somkin, C.P., and Adler, N.E. (2004). Local services and amenities, neighborhood social capital, and health. Social Science \& Medicine 59: 1219-1229. doi:10.1016/j.socscimed.2004.01.008.

Balfour, J.L. and Kaplan, G.A. (2002). Neighborhood environment and loss of physical function in older adults: evidence from the Alameda County Study. American Journal of Epidemiology 155(6): 507-515. doi:10.1093/aje/155.6.507.

Bécares, L, Nazroo, J., and Stafford, M. (2009). The buffering effects of ethnic density on experienced racism and health. Health \& Place 15(3): 670-678. doi:10.1016/j.healthplace.2008.10.008.

Beenackers, M.A., Kamphuis C. B.M., Burdorf, A., Mackenbach, J.P., and van Lenthe, F.J. (2013). Why some walk and others don't: exploring interactions of perceived safety and social neighborhood factors with psychosocial cognitions. Health Education Research 28(2): 220-233. doi:10.1093/her/cyt002.

Bjornstrom, E.E.S. and Kuhl, D.C. (2014). A different look at the epidemiological paradox: Self-rated health, perceived social cohesion, and neighborhood immigrant context. Social Science \& Medicine 120: 118-125. doi:10.1016/j. socscimed.2014.09.015.

Boslaugh, S.E., Luke, D.A., Brownson, R.C., Naleid, K., and Kreuter, M. (2004). Perceptions of neighborhood environment: Is it "Who you are" or "Where you live". Journal of Urban Health: Bulletin of the New York Academy of Medicine 81(4): 671-681.

Browning, C.R., Cagney, K.A., and Wen, M. (2003). Explaining variation in health status across space and time: implications for racial and ethnic disparities in selfrated health. Social Science \& Medicine 57: 1221-1235. doi:10.1016/S02779536(02)00502-6.

Brownson, R.C., Hoehner, C.M., Day, K., Forsyth, A., and Sallis, J.F. (2009). Measuring the built environment for physical activity: State of the science. American Journal of Preventive Medicine 36(4s): S99-S123. doi:10.2148/benv. 35.1.122. 
Burton, L.M. and Jarrett, R.L. (2000). In the mix, yet on the margins: The place of families in urban neighborhood and child development research. Journal of Marriage and the Family 62: 1114-1135. doi:10.1111/j.1741-3737.2000.01 114.x.

Chiricos, T., McEntire, R., and Gertz, M. (2001). Perceived racial and ethnic composition of neighborhood and perceived risk of crime. Social Problems 48: 322-340. doi:10.1525/sp.2001.48.3.322.

Chen, J. (2011). Internal migration and health: Re-examining the healthy migrant phenomenon in China. Social Science \& Medicine 72: 1294-1301. doi:10.1111/j.1468-2435.2009.00589.x.

Chen, J. (2013). Perceived discrimination and subjective well-being among rural-tourban migrants in China. Journal of Sociology \& Social Welfare 40(1): 131-156.

Chen, J. and Chen, S. (2015). Mental health effects of perceived living environment and neighborhood safety in urbanizing China. Habitat International 46: 101-110. doi:j.habitatint.2014.11.002.

Chen, R., Kan, H., Chen, B., Huang, W., Bai, Z., Song, G., and Pan, G. (2012). Association of particulate air pollution with daily mortality: The China Air Pollution and Health Effects Study. American Journal of Epidemiology 175(11): 1173-1181. doi:10.1093/aje/kwr425.

Choi, J.Y. (2009). Contextual effects on health care access among immigrants: Lessons from three ethnic communities in Hawaii. Social Science \& Medicine 69: 1261-1271. doi:10.1016/j.socscimed.2009.08.001.

Clarke, P., Morenoff, J., Debbink, M., Golberstein, E., Elliott, M.R., and Lantaz, P.M. (2014). Cumulative exposure to neighborhood context: Consequences for health transitions over the adult life course. Research on Aging 36(1): 115-142. doi:10.1177/0164027512470702.

Cohen, S., Kamarck, T., and Mermelstein, R. (1983). A global measure of perceived stress. Journal of Health and Social Behavior 24: 385-396. doi:10.2307/2136 404.

Démurger, S., Gurgand, M., Li, S., and Yue, X. (2009). Migrants as second-class workers in urban China? A decomposition analysis, Journal of Comparative Economics 37: 610-628. doi:10.1016/j.jce.2009.04.008. 
Diez Roux, A.V. (2001). Investigating neighborhood and area effects on health. American Journal of Public Health 91: 1783-1789. doi:10.2105/AJPH.91.11. 1783.

Diez Roux, A.V. and Mair, C. (2010). Neighborhood and health. Annals of the New York Academy of Sciences 1186: 125-145. doi:10.1111/j.1749-6632.2009. 05333.x.

Diez Roux, A.V., Nieto, J., Muntamer. C., Tyroler, H. A., Comstock, G.W., Shahar, E., Cooper, L.S., Watson, R.L., and Szklo, M. (1997). Neighborhood environments and coronary heart disease: A multilevel analysis. American Journal of Epidemiology 146: 48-63. doi:10.1093/oxfordjournals.aje.a009191.

Do, D.P., Finch, B.K., Basurto-Davila, R., Bird, C., Escarce, J., and Lurie, N. (2008). Does place explain racial health disparities? Quantifying the contribution of residential context to the black/white health gap in the United States. Social Science \& Medicine 67: 1258-1268. doi:10.1016/j.socscimed.2008.06.018.

Downey, L. (2006). Environmental inequality in metropolitan America in 2000. Sociological Spectrum 26: 21-41. doi:10.1080/02732170500256716.

Ellaway, A., Macintyre, S., and Kearns. A. (2001). Perceptions of place and health in socially contrasting neighbourhoods. Urban Studies 38: 2299-2316. doi:10.1080/00420980120087171.

Ellis, M. and Almgren, G. (2009) (eds.). Local contexts of immigrant and secondgeneration integration in the United States. Special issue of Journal of Ethnic and Migration Studies 35(7). Routlege.

Elo, I.T., Mykyta, L., Margolis, R., and Culhane, J.F. (2009). Perceptions of neighborhood disorder: The role of individual and neighborhood characteristics. Social Science Quarterly 90(5): 1298-1320. doi:10.1111/j.1540-6237.2009. 00657.x.

Everson-Rose, S.A., Skarupski, K.A., Barnes, L.L., Beck, T., Evans, D., and Mendes de Leon, C.F. (2011). Neighborhood socioeconomic conditions are associated with psychosocial functioning in older black and white adults. Health \& Place 17(3): 793-800. doi:10.1016/j.healthplace.2011.02.007.

Forst, S.S., Goins, R.T., Hunter, R.H., Hooker, S.P., Bryant, L.L., Kruger, J., and Pluto, D. (2010). Effects of the built environment on physical activity of adults living in rural settings. American Journal of Health Promotion 24(4): 267-283. doi:10.4278/ajhp.08040532. 
Gu, Zhu \& Wen: Neighborhood-health links: Differences between migrants and natives in Shanghai

Geelen, L.M.J., Huijbregts, M.A.J., den Hollander, H., Ragas, A.M.J., van Jaarsveld, H.A., and de Zwart, D. (2009). Confronting environmental pressure, environmental quality and human health impact indicators of priority air emissions. Atmospheric Environment 43: 1613-1621. doi:10.1016/j.atmosenv. 2008.12.002.

Hadley-Ives, E., Stiffman, A.R., Elze, D., Johnson, S.D., and Dore, P. (2000). Measuring neighborhood and school environments: Perceptual and aggregate approaches. Journal of Human Behavior in the Social Environment 3(1): 1-28. doi:10.1300/J137v03n01_01.

Hill, E.M., Shepherd, D., Welch, D., Dirks, K.N., and McBridge, D. (2012). Perceptions of neighborhood problems and health-related quality of life. Journal of Community Psychology 40(7): 814-827. doi:10.1002/jcop.21490.

Hiott, A.E., Grzywacz, J.G., Davis S.W., Quandt S.A., and Arcury T.A. (2008). Migrant farmworker stress: mental health implications. Journal of Rural Health 24(1): 32-39. doi:10.1111/j.1748-0361.2008.00134.x.

Hyman, I. (2004). Setting the stage: Reviewing current knowledge on the health of Canadian immigrants: what is the evidence and where are the gaps? Canadian Journal of Public Health 95(3): I-3-I-8.

Jack, E. and McCormack, G.R. (2014). The associations between objectivelydetermined and self-reported urban form characteristics and neighborhood-based walking in adults. International Journal of Behavioral Nutrition and Physical Activity 11: e71. doi:10.1186/1479-5868-11-71.

Jin, L., Wen, M., Fan, J.X., and Wang, G. (2012). Trans-local ties, local ties and psychological well-being among rural-to-urban migrants in Shanghai. Social Science \& Medicine 75: 288-296. doi:10.1016/j.socscimed.2012.03.014.

Kamphius, C, B.M., Mackenbach, J.P., Giskes, K., Huisman, M., Brug, J., and van Lenthe, F.J. (2010). Why do poor people perceive poor neighborhoods? The role of objective neighborhood features and psychosocial factors. Health \& Place 16: 744-754. doi:10.1016/j.healthplace.2010.03.006.

Kawachi, I. and Berkman, L. (2000). Social cohesion, social capital, and health. In: Berkman, L.F. and Kawachi, I. (eds.). Social epidemiology. London: Oxford University Press: 174-190.

Kawachi, I. and Berkman, L.F. (2003). Introduction. In Kawachi, I. and Berkman, L.F. (eds.). Neighborhoods and health. New York: University of Oxford Press: 1-19. doi:10.1093/acprof:oso/9780195138382.001.0001. 
Kim, D., Baum, C.F., Ganz, M., Subramanianb,S.V., and Kawachib, I. (2011). The contextual effects of social capital on health: A cross-national instrumental variable analysis. Social Science \& Medicine 73(12): 1689-1697. doi:10.1016/j. socscimed.2011.09.019.

Kimbro, R.T. (2009). Acculturation in context: Gender, age at migration, neighborhood ethnicity, and health behavior. Social Science Quarterly 90(5): 1145-1166. doi:10.1111/j.1540-6237.2009.00651.x.

Labovitz S. (1968). Criteria for selecting a significance level: a note on the sacredness of .05. The American Sociologist 3(3): 220-222.

Li, X., Stanton, B., Fang, X., Xiong, Q., Yu, S., Lin, D., Hong, Y., Zhang, L., Chen, X., and Wang, B. (2009). Mental health symptoms among rural-to-urban migrants in China: A comparison with their urban and rural counterparts. World Health \& Population 11(4): 15-29. doi:10.12927/whp.2009.20868.

Li, Y. and Wu, S. (2010). Social networks and health among rural-urban migrants in China: A channel or a constraint? Health Promotion International 25(3): 371380. doi:10.1093/heapro/daq020.

Logan, J.R., Alba, R.D., and Zhang, W. (2002). Immigrant enclaves and ethnic communities in New York and Los Angeles. American Sociological Review 67(2): 299-322. doi:10.2307/3088897.

McDonald, R.I., Forman, R.T.T., and Kareiva, P. (2010). Open space loss and land inequality in United States' cities, 1990-2000. PLoS ONE 5(3): e9509. doi:10.1371/journal.pone.0009509.

Macintyre, S., Ellaway, A., and Cummins, S. (2002). Place effects on health: how can we conceptualise, operationalise and measure them? Social Science \& Medicine 65 (1): 125-139. doi:10.1016/S0277-9536(01)00214-3.

Mair, C, Diez Roux, A.V., and Galea, S. (2008). Are neighborhood characteristics associated with depressive symptoms? A review of evidence. Journal of Epidemiology and Community Health 62(11): 940-946.

National Bureau of Statistics of China (NBSC). (2012). The tabulation of the 2010 population census of the People's Republic of China. Beijing: China Statistics Press.

Nunnally, J.C. (1994). Psychological theory. $3^{\text {rd }}$ ed. New York: McGraw-Hill. 
O'Brien, D.T., Norton, C.C., Cohen, J., and Wilson, D.S. (2014). Local adaptation in community perception: How background impacts judgments of neighborhood safety. Environment and Behavior 26(2): 213-246. doi:10.1177/001391651245 6844.

O’Campo, P., Salmon, C., and Burke, J. (2009). Neighbourhoods and mental wellbeing: what are the pathways? Health \& Place 15: 56-68. doi:10.1016/j.health place.2008.02.004.

Palmer, N.A., Perkins, D.D., and Xu, Q. (2011). Social capital and community participation among migrant workers in China. Journal of Community Psychology 39(1): 89-105. doi:10.1002/jcop.20419.

Polling, C., Khondoker, M, SLECoH study team, Hatch, S.L., and Hotopf, M. (2014). Influence of perceived and actual neighborhood disorder on common mental illness. Social Psychiatry \& Psychiatric Epidemiology 49: 889-901. doi:10.1007/s00127-013-0813-9.

Poortinga, W., Dunstan, F.D., and Fone, D.L. (2007). Perceptions of the neighborhood environment and self rated health: a multilevel analysis of the Caerphilly Health and Social Needs Study. BMC Public Health 7: 285. doi:10.1186/1471-2458-7285.

Roosa, M.W., White, R. M.B., Zeiders, K.H., and Tein, J.-Y. (2009). An examination of the role of perceptions in neighborhood research. Journal of Community Psychology 37(3): 327-341. doi:10.1002/jcop.20298.

Ross, C.E. and Jang, S.S. (2000). Neighborhood disorder, fear, and mistrust: The buffering role of social ties with neighbors. American Journal of Community Psychology 28: 401-420. doi:10.1023/A:1005137713332.

Ross, C.E., Mirowsky, J., and Pribesh, S. (2001). Powerlessness and the amplification of threat: Neighborhood disadvantage, disorder, and mistrust. American Sociological Review 66: 568-591. doi:10.2307/3088923.

Sallis, J.F., Cervero, R.B., Ascher, W., Henderson, K.A., Kraft, M.K., and Kerr, J. (2006). An ecological approach to creating active living communities. Annual Review of Public Health 27: 297-322. doi:10.1146/annurev.publhealth. 27.021405.102100.

Sallis, J.F., Saelens, B.E., Frank, L.D., Conway, T.L., Slymen, D.J., Cain, K.L., Chapman, J.E, and Kerr, J. (2009). Neighborhood built environment and income: examining multiple health outcomes. Social Science \& Medicine 68(7): 1285-1293. doi:10.1016/j.socscimed.2009.01.017. 
Semyonov, M., Gorodzeisky, A., and Glikma, A. (2012). Neighborhood ethnic composition and resident perceptions of safety in European countries. Social Problems 59(1): 117-135. doi:10.1525/sp.2012.59.1.117.

Schaefer-McDaniel, N., Dunn, J.R., Minian, N., and Katz, D. (2010). Rethinking measurement of neighborhood in the context of health research. Social Science \& Medicine 71(4): 651-656. doi:10.1016/j.socscimed.2010.03.060.

Schulz, A.J., Kannan, S., Dvonch, T., Isral, B.A., Allen, A., James, S.A., House, J.S., and Leopkowski, J. (2005). Social and physical environments and disparities in risk for cardiovascular disease: The healthy environments partnership conceptual model. Environmental Health Perspective 113: 1817-1825. doi:10.1289/ehp. 7913.

Schulz, A.J., Mentz, G., Lachance, L., Zenk, S.N., Johnson, J., Stokes, C., and Mandell, R. (2013). Do observed or perceived characteristics of the neighborhood environment mediate association between neighborhood poverty and cumulative biological risk? Health Place 24: 147-156. doi:10.1016/j.healthplace. 2013.09.005.

Shanghai Municipal Statistical Bureau (2011). Shanghai Statistical Yearbook 2011. Shanghai: Shanghai Municipal Statistical Bureau.

Siordia, C. and Saenz, J. (2013). On the relationship between neighborhood perception, length of residence and co-ethnic concentration. Applied Spatial Analyses and Policy 6(4): 267-284. doi:10.1007/s12061-013-9084-9.

Stafford, M., Newbold, B., and Ross, N. (2011). Psychological distress among immigrants and visible minorities in Canada: a contextual analysis. International Journal of Social Psychiatry 57(4): 428-441. doi:10.1177/0020764010365407.

Telles, E.E. and Ortiz, V. (2008). Generations of exclusion: Mexican Americans, assimilation, and race. New York: Russell Sage Foundation.

Vega, W.A., Ang, A., Rodriguez, M.A., and Finch, B.K. (2011). Neighborhood protective effects on depression in Latinos. American Journal of Community Psychology 47: 114-126. doi:10.1007/s10464-010-9370-5.

Van Dyck, D., Cerin, E., Conway, T.L., De Bourdeaudhuij, I., Owen, N., Kerr, J., Cardon, G., Frank, L.D., Saelens, B.E., and Sallis, J.F. (2012). Associations between perceived neighborhood environmental attributes and adults' sedentary behavior: Findings from the USA, Australia and Belgium. Social Science \& Medicine 74(9): 1375-1384. doi:10.1016/j.socscimed.2012.01.018. 
Gu, Zhu \& Wen: Neighborhood-health links: Differences between migrants and natives in Shanghai

Wachs, T. (1999). Celebrating complexity. Conceptualization and assessment of the environment. In: Freidman, S. and Wachs, T. (eds.). Measuring environment across the life span: Emerging methods and concepts. Washington, DC: American Psychological Association: 357-392. doi:10.1037/10317-012.

Ward, L.S. and Tanner, A.D. (2010). Psychosocial stress and health-related quality of life for Latino migrant farmworkers. Southern Online Journal of Nursing Research 10(1).

Weden, M.M., Carpiano, R.M., and Robert, S.A. (2008). Subjective and objective neighborhood characteristics and adult health. Social Science \& Medicine 66: 1256-1270. doi:10.1016/j.socscimed.2007.11.041.

Wen, M., Fan, J., Jin, L., and Wang, G. (2010). Neighborhood effects on health among migrants and natives in Shanghai, China. Health \& Place 16: 452-460. doi:10.1016/j.healthplace.2009.12.001.

Wen, M., Hawkley L.C., and Cacioppo, J.T. (2006). Objective and perceived neighborhood environment, individual SES and psychosocial factors, and selfrated health: An analysis of older adults in Cook County, Illinois. Social Science \& Medicine 63: 2575-2590. doi:10.1016/j.socscimed.2006.06.025.

Wen, M. and Wang, G. (2009). Demographic, psychological, and social environmental factors of loneliness and satisfaction among rural-to-urban migrants in Shanghai, China. International Journal of Comparative Sociology 50(2): 155-162. doi:10.1177/0020715208101597.

Weishaar, H.B. (2008). Consequences of international migration: a qualitative study on stress among Polish migrant workers in Scotland. Public Health 122(11): 12501256. doi:10.1016/j.puhe.2008.03.016.

Woodward, M. (2004). Epidemiology: Study design and data analysis. Second Edition. London: Taylor \& Francis.

World Health Organization (2000). Obesity: preventing and managing the global endemic, WHO Technical Report Series No. 894 WHO: Geneva.

Wu, F. (2012). Neighborhood attachment, social participation and willingness to stay in China's low-income communities. Urban Affairs Review 48(4): 547-570. doi:10.1177/1078087411436104. 
Yen, I.H., Yelin, E., Katz, P., Eisner, M.D., Blanc, P.D. (2008). Impact of perceived neighborhood problems on change in asthma-related health outcomes between baseline and followup. Health \& Place 14(3): 468-477. doi:10.1016/j.health place.2007.09.003.

Zhang, J., Li, X., Fang, X., and Xiong, Q. (2009). Discrimination experience and quality of life among rural-to-urban migrants in China: The mediation effect of expectation-reality discrepancy. Quality of Life Research 18: 291-300. doi:10.1007/s11136-009-9454-6. 
Gu, Zhu \& Wen: Neighborhood-health links: Differences between migrants and natives in Shanghai

\section{Appendix}

Table A: Sample size needed to draw robust conclusions given sample means and variance

\begin{tabular}{|c|c|c|c|c|}
\hline & $\begin{array}{l}\text { Neighborhood } \\
\text { cohesion }\end{array}$ & $\begin{array}{l}\text { Neighborhood } \\
\text { safety }\end{array}$ & $\begin{array}{l}\text { Neighborhood } \\
\text { amenities }\end{array}$ & $\begin{array}{c}\text { Good air } \\
\text { quality }\end{array}$ \\
\hline \multicolumn{5}{|l|}{ Migrant workers } \\
\hline \multicolumn{5}{|c|}{ Sample size needed for a significance at $p<0.1$ with power $=0.8$} \\
\hline $\begin{array}{l}\text { Self-rated } \\
\text { poor/fair health }\end{array}$ & 26 & 43 & 44 & 133 \\
\hline $\begin{array}{l}\text { Perceived social } \\
\text { stress }\end{array}$ & 62 & 64 & 37 & 27 \\
\hline $\begin{array}{l}\text { Having 1+ chronic } \\
\text { disease }\end{array}$ & 181 & 387 & 114 & 82 \\
\hline $\begin{array}{l}\text { Actual sample } \\
\text { size of the largest } \\
\text { category of the } \\
\text { variable }\end{array}$ & 259 & 213 & 92 & 334 \\
\hline \multicolumn{5}{|l|}{ Native residents } \\
\hline \multicolumn{5}{|c|}{ Sample size needed for a significance at $p<0.1$ with power $=0.8$} \\
\hline $\begin{array}{l}\text { Self-rated } \\
\text { poor/fair health }\end{array}$ & 74 & 103 & 14 & 224 \\
\hline $\begin{array}{l}\text { Perceived social } \\
\text { stress }\end{array}$ & 137 & 357 & 23 & 96 \\
\hline $\begin{array}{l}\text { Having 1+ chronic } \\
\text { disease }\end{array}$ & 257 & 74 & 46 & 138 \\
\hline $\begin{array}{l}\text { Actual sample } \\
\text { size of the largest } \\
\text { category of the } \\
\text { variable }\end{array}$ & 313 & 253 & 131 & 361 \\
\hline
\end{tabular}

